\title{
O DESENVOLVIMENTO DE ATIVIDADES TURÍSTICAS NO MUNICÍPIO DE PRESIDENTE EPITÁCIO-SP
}

Suélen Daianne de Oliveira

Universidade Estadual Paulista "Júlio de Mesquita Filho" - UNESP, Mestrado em Geografia. E-mail: suelendaianne@hotmail.com

\section{RESUMO}

A cidade de Presidente Epitácio está localizada às margens do Rio Paraná, considerado um dos rios mais importantes do país devido a sua expressiva vazão hídrica e sua imensa extensão. 0 município sofreu grandes transformações em seu território em virtude da construção da Usina Hidrelétrica Engenheiro Sérgio Motta em Porto Primavera-SP. Entretanto, os reservatórios formados pela implantação de usinas hidrelétricas proporcionam o uso múltiplo das águas e a beleza paisagística constituída pela formação do reservatório propiciou um cenário ideal para prática de atividades náuticas, de lazer, esportivas e de turismo. A atividade turística surge como uma oportunidade de diversificação da economia e uma estratégia para o desenvolvimento local, no entanto, a cidade enfrenta algumas dificuldades para alavancar o turismo. 0 tema foi proposto porque acredita-se na necessidade de se ampliar as discussões sobre o uso dos reservatórios para o desenvolvimento do turismo local.

Palavras-chave: Turismo. Reservatório. Uso múltiplo das águas. Usina hidrelétrica. Desenvolvimento local.

\section{THE DEVELOPMENT OF TOURIST ACTIVITIES IN THE MUNICIPALITY OF PRESIDENTE EPITÁCIO-SP}

\section{ABSTRACT}

The city of Presidente Epitácio is located on the banks of the Paraná River, considered one of the most important rivers in the country due to its expressive water flow and its immense extension. The municipality underwent major transformations in its territory due to the construction of the Engenheiro Sérgio Motta Hydroelectric Power Plant in Porto Primavera-SP. However, the reservoirs formed by the implantation of hydroelectric plants provide the multiple use of the waters and the scenic beauty constituted by the formation of the reservoir provided an ideal scenario for practicing nautical, leisure, sports and tourism activities. The tourism activity emerges as an opportunity for diversification of the economy and a strategy for local development, however, the city faces some difficulties to leverage tourism. The theme was proposed because it is believed in the need to broaden the discussions about the use of reservoirs for the development of local tourism.

Key-words: Tourism. Reservoir. Multiple use of the waters. Hydroelectric power plant. Local development.

\section{INTRODUÇÃO}

A Estância Turística de Presidente Epitácio está localizada no extremo oeste do Estado de São Paulo na divisa com o Estado do Mato Grosso do Sul. Situado às margens do Rio Paraná que foi transformado em reservatório da Usina Hidrelétrica Engenheiro Sérgio Motta (também conhecida como Usina de Porto Primavera), o município conta com inúmeras belezas naturais.

Em 1990, Presidente Epitácio recebeu o título de Estância Turística do governo do Estado de São Paulo por sua vocação à atividade e localização geográfica privilegiada além de seus 
recursos naturais, atrativos históricos, culturais e artísticos (BOMFIM, 2007, p. 39). "As Estâncias Turísticas são cidades com muitas tradições culturais, patrimônios históricos, artesanatos, lindas paisagens, centros de lazer, além de ótimos serviços de gastronomia" (SÃO PAULO, 2017).

A partir do momento que recebeu o título de estância, o município começou a receber apoio financeiro do Departamento de Apoio ao Desenvolvimento dos Municípios Turísticos (DADETUR), órgão vinculado, à época, à Secretaria Estadual de Esporte e Turismo.

De acordo com Camargo (2008, p. 53) o município apresenta uma "grande vocação" para o turismo que surgiu com atividades relacionadas ao lazer e às festividades.

O que hoje se apresenta como "vocação" teve sua origem nas atividades relacionadas ao lazer, às festividades e aos lugares de encontro que surgiram no decorrer da constituição e crescimento do município, mediante a apropriação, pela comunidade local, de determinadas áreas, em especial as vinculadas ao Rio Paraná e seu entorno. Tais áreas sempre foram utilizadas pela população local e circunvizinhança para comemorações, encontros e festejos, constituindo-se num movimento espontâneo de união entre a própria comunidade local (CAMARGO, 2008, p. 53).

No entanto, Bomfim (2007, p. 12) afirma que a atividade turística em Presidente Epitácio deve ser dividida em duas fases: antes e depois da implantação da UHE Engenheiro Sérgio Motta.

No município de Presidente Epitácio, o desenvolvimento turístico encontra-se dividido em duas fases distintas: a primeira, anterior a implantação da Usina Hidrelétrica Engenheiro Sérgio Motta, em Porto Primavera, modelo de crescimento que se fixou tendo por referência a prática do lazer no antigo Parque Municipal Figueiral, nas ilhas e praias naturais e da pesca no rio Paraná, mesclado à participação em inúmeros festejos de caráter popular e religioso; a segunda, com a formação do grande lago, que nasceu como conseqüência da necessidade da produção de energia elétrica para abastecimento em nível nacional e de se criar a hidrovia Tietê-Paraná, vindo a ocorrer em Presidente Epitácio e em todos os municípios lindeiros os mais diversos impactos, como o desaparecimento de ecossistemas, perdas territoriais e de patrimônios históricos e culturais e a desestruturação de setores sociais e econômicos (BOMFIM, 2007, p. 12).

Dessa forma, o presente estudo tem como objetivo analisar a situação atual, enfatizar as potencialidades e identificar os problemas que reprimem o desenvolvimento do turismo no município.

\section{METODOLOGIA}

O presente trabalho foi desenvolvido utilizando como procedimento a pesquisa bibliográfica. Segundo Gil (1994) a pesquisa bibliográfica possibilita alcançar uma gama de informações dispersas em inúmeras publicações que auxiliam na construção ou na melhor definição do conceito que envolve o objeto de estudo proposto.

Para a realização desta pesquisa buscou-se levantar informações em livros, artigos científicos, dissertações, site oficiais, entre outros. Desta forma, possibilitou o levantamento de informações sobre o tema pesquisado e a análise do desenvolvimento do turismo no município. 
Além disso foi examinado o Plano Diretor do Município e também foi consultado o Conselho Municipal de Turismo para descobrir o andamento das ações de fomento da atividade turística.

\section{RESULTADOS}

Analisamos o Plano Diretor da Estância Turística de Presidente Epitácio. Nele existe um capítulo reservado ao turismo no qual destaca que o poder público municipal deve incentivar o turismo como fator estratégico de desenvolvimento econômico, e ainda: "II - articular programas e ações turístico-culturais, explorando as diversidades, como a bacia do rio Paraná". Porém, o plano diretor é o instrumento básico da política de desenvolvimento e expansão urbana. Para ações mais eficazes para o fomento da atividade turística é necessária a elaboração de um plano diretor de turismo. No entanto, o município ainda não possui um Plano Diretor de Turismo, documento importante que estabelece as diretrizes para a condução da atividade turística no município, apesar do mesmo ter se tornado obrigatório para municípios classificados como estâncias turísticas.

\section{DISCUSSÃO}

O município de Presidente Epitácio teve sua paisagem transformada com a construção da UHE Engenheiro Sérgio Motta. O enchimento do reservatório foi feito em duas etapas: a primeira foi concluída em dezembro de 1998, e a segunda, em março de 2001 . No total dezesseis municípios dos estados de São Paulo e Mato Grosso do Sul foram atingidos pela usina, sendo onze em São Paulo (Rosana, Teodoro Sampaio, Presidente Epitácio, Caiuá, Presidente Venceslau, Ouro Verde, Santa Mercedes, São João do Pau D'Alho, Panorama, Paulicéia e Castilho) e cinco no Mato Grosso do Sul (Três Lagoas, Santa Rita do Pardo, Bataguassú, Anaurilândia e Brasilândia). Do lado paulista, Presidente Epitácio foi o mais atingido com 21.249,53 hectares de área alagada, isto é, $19,40 \%$ da área total do município (CESP, 1994).

Em Presidente Epitácio, entre os diversos impactos ocasionados pela UHE Engenheiro Sérgio Motta, destacamos a alterações de ecossistemas como o Varjão do rio Paraná - representado pela Reserva Estadual Lagoa São Paulo, que foi alagada em $85 \%$ de sua área e abrigava diversas espécies da fauna e da flora, inclusive algumas em extinção; ocorreu supressão de ecossistemas como destruição de parte de um dos últimos trechos de planície de inundação do Alto rio Paraná e significativos trechos de mata nativa da região, mata ciliar, além de inundar o habitat natural de inúmeras espécies de animais vertebrados. As águas cobriram pelo menos 77 ilhas no trecho do reservatório, das quais 46 eram habitadas, conforme cadastro da CESP. Há que se destacar que uma das maiores perdas para o município de Presidente Epitácio em termos de flora e fauna foi a supressão da Reserva Estadual Lagoa São Paulo criada pelo Decreto Lei $N^{\circ} 13.049$ de novembro de 1942. A reserva tinha 14.200 hectares e abrigava inúmeras espécies vegetais e animais, sendo algumas espécies ameaçadas de extinção, além de sete lagoas. Do total, restaram apenas 3.500 hectares (SANTOS e LEAL, 2009, p. 05).

A população epitaciana presenciou a transformação de seu território e sofreu com a supressão de cerca de trinta ilhas e o antigo Parque Figueiral, locais bastante frequentados pelos moradores e também por turistas, conforme apontam Camargo e Silva: 
Além do desaparecimento de quase trinta ilhas, que eram visitadas por turistas que desfrutavam de suas praias, outro local importante para o lazer que constituía o maior ponto de fluxo turístico do município e desapareceu com a subida das águas foi o antigo Parque Figueiral. Situado na barranca do Rio Paraná, a três quilômetros do centro da cidade, era dotado de infra-estrutura como barracas, lanchonetes, praia, área de camping, chuveiros e estacionamento. Possuía área verde, composta de vegetação rasteira e figueiras centenárias. Este local era bastante freqüentado pela população local, que demonstrava um apego especial pelo mesmo, principalmente em virtude de suas formas físicas naturais e proximidade com o rio (CAMARGO e SILVA, 2005, p. 250).

Devido aos impactos causados pela implantação da usina a CESP foi obrigada a realizar obras de mitigação e compensação. Ela propôs um projeto, em parceria com o poder público, para a construção de equipamentos e remodelação do espaço para a prática de lazer e desenvolvimento do turismo na cidade, como uma forma de "recompensa" pelas diversas perdas que a cidade sofreu com a subida das águas e formação do Grande Lago (CAMARGO e SILVA, 2005).

As obras mais importantes para o turismo foram as construções do Novo Parque Figueiral e da Orla Fluvial. O Novo Figueiral, localizado a aproximadamente cinco quilômetros do centro da cidade, possui: praia, quiosques, lanchonetes, restaurante, plataforma para pesca, área de camping, palco com camarins, quadras poliesportivas, atracadouro, rampa para barcos, pista de motocross, estacionamento e posto do corpo de bombeiros. Na Orla Fluvial, com aproximadamente $7 \mathrm{~km}$ de extensão, encontramos: ciclovia, parques infantis, anfiteatro, lanchonetes, aparelhos fixos para exercícios de condicionamento físico, pavilhão de eventos, pista de skate e quadra de basquete. No quadro abaixo podemos visualizar outras obras realizadas pela CESP no município.

Quadro 1: Obras realizadas pela CESP no município de Presidente Epitácio-SP.

\begin{tabular}{|c|c|}
\hline Obras compensatórias & Obras mitigatórias \\
\hline Anel Viário & Reflorestamento \\
\hline $\begin{array}{c}\text { Centro Comunitário do } \\
\text { Reassentamento Urbano }\end{array}$ & Encabeçamento da Ponte Maurício Joppert \\
\hline Reassentamento Urbano & Matadouro Municipal \\
\hline Duplicação LT. 34,5/138KV & Poços e redes em agrovilas \\
\hline Escola Municipal & Relocação do porto fluvial \\
\hline Parque “O Figueiral” & Relocação dos portos de areia \\
\hline Píer Turístico & Proteção das encostas \\
\hline Ciclovia/ Passarela Ribeirão Caiuá & Relocação da estação de captação/adutora da \\
Sabesp
\end{tabular}

Fonte: CESP (apud Cintra, 2010)

A construção do Novo Parque Figueiral e da Orla Fluvial impulsionaram a atividade turística, além disso, o reservatório também criou um ambiente favorável para o turismo de pesca e lazer náutico.

Colloquium Socialis, Presidente Prudente, v. 01, n. Especial 2, Jul/Dez, 2017, p.844-852. DOI: 10.5747/cs.2017.v01.nesp2.s0238 
Foi, portanto, após este período (década de 1980), que a atividade turística passou a ser considerada como a "grande vocação" e futuro promissor da cidade, atraindo investimentos do poder público e da iniciativa privada. Após as intervenções da CESP com a construção e adequação de áreas funcionalizadas para a prática do lazer e do turismo foi dado um novo impulso através da divulgação de tais estruturas (CAMARGO, 2008, p. 127).

A cidade de Presidente Epitácio está localizada às margens do Rio Paraná, considerado um dos rios mais importantes do país, quer pela sua abundância hídrica ou pela sua extensão. Possui belezas naturais exuberantes e corpos d'água que permitem a prática de turismo náutico, de sol e praia, além de potencialidades para o desenvolvimento do turismo rural, cultural e de aventura. Dentre as atividades com potencial para serem desenvolvidas no reservatório ou às suas margens destacam-se os esportes aquáticos como: canoagem, windsurfe, vela, stand up paddle, além de passeios com lancha, jet-ski, caiaque, jangada e banana-boat. Além disso, é possível desenvolver atividades de lazer em praias fluviais, pesca esportiva e ecoturismo (trilhas ecológicas, mergulho, caminhadas, safáris fotográficos, entre outros).

Dessa forma, o reservatório formado pela barragem de Porto Primavera, criado para a geração de energia elétrica pode ser aproveitado também para a prática de turismo, uma alternativa de desenvolvimento para o município afetado pelo empreendimento.

Entretanto, como aspectos positivos, sobretudo da implantação da Usina Hidrelétrica Engenheiro Sérgio Motta (Porto Primavera), destacam-se os investimentos na infra-estrutura provenientes de medidas compensatórias como a melhoria de estradas, construção de pontes e do Parque da Orla Fluvial que se constituiu como um novo atrativo de lazer, entre outros benefícios. Ressalta-se as inúmeras pousadas e pesqueiros que se instalaram ao redor da represa, disseminação de esportes náuticos e incremento de outras festividades. Esses são aspectos positivos que favorecem ao turismo e ao seu crescimento. No entanto, o município possui um grande potencial turístico em virtude de suas belezas naturais que necessita cada vez mais ser explorado e estruturado adequadamente (SOUZA e SANTOS, 2011, p. 4).

"O Rio Paraná sempre foi de singular importância para a história da cidade, desde seu surgimento até o direcionamento das atividades econômicas na região". (CAMARGO, 2008, 105). As transformações ocorridas em decorrência da construção da Usina Hidrelétrica Engenheiro Sérgio Motta representam um marco importante no processo de mudanças socioespaciais no município. Após o represamento do rio, Presidente Epitácio vivencia uma fase de adaptação à nova realidade. "Assim, o, Grande Lago, passa a ser "vendido" como o principal atrativo turístico da região" (CINTRA, 2010, p. 50). A prefeitura municipal começa a divulgar o município chamandoo de Porto das Águas, ressalta que a cidade possui a maior piscina natural de água doce do estado de São Paulo e convida a população, através de propagandas em jornais regionais, a conhecer e a praticar esportes aquáticos, atividade pesqueira e lazer náutico no lago (CINTRA, 2010).

Cintra (2010, p. 100) declara que "o rio Paraná e sua piscosidade sempre foram um dos maiores atrativos turísticos da estância, tanto que um dos principais eventos que impulsionou o turismo foi o Festival da Pesca iniciado na década de 1980 e que ganhou título de Nacional pela dimensão que tomou na década de 1990".

Souza e Oliveira (2011) relatam que após as transformações que permitiram o surgimento de vários atrativos e atividades ligadas à pesca, organizou-se a infraestrutura e equipamentos para a realização da atividade turística como: guias de pesca, marina, hotéis e pousadas. Cita ainda que 
o município passou a realizar eventos anuais como: Carnaval, Festa de Nossa Senhora dos Navegantes e Festival de Turismo, os quais são realizados na orla e no balneário municipal. Esses eventos ainda são realizados nos dias de hoje e atraem muitos turistas para o município.

Os mesmos autores também destacam outras mudanças no município como: a transição da economia ceramista para turística; a especulação imobiliária as margens do rio Paraná através dos loteamentos, as transformações ambientais pelo setor privado e público e o direcionamento das políticas públicas (SOUZA e OLIVEIRA, 2011).

Os dados referentes ao desenvolvimento hoteleiro no Município apontam para a prevalência de pequenos e médios estabelecimentos com até 30 apartamentos, sendo que a maioria dos estabelecimentos foi implantada a partir do enchimento do Lago da Usina Hidrelétrica Engenheiro Sérgio Motta (Porto Primavera) (SOUZA e OLIVEIRA, 2011, p. 05).

Atualmente, o rio Paraná continua sendo o maior atrativo turístico da estância. Grande parte dos turistas que visitam a cidade são pescadores que vêm em busca do Tucunaré, peixe do gênero exótico, muito apreciado para pesca esportiva que tem se destacado na região após o represamento do rio. A vantagem desta espécie é que a pesca é permitida até mesmo no período da piracema, respeitando-se os locais, tamanhos mínimos e limitações. Além disso, o turismo náutico também tem se destacado no município.

A Estância Turística de Presidente Epitácio ficou reconhecida nacionalmente quando venceu a batalha do pôr do sol mais bonito do Brasil, concurso realizado pelo Fantástico ${ }^{1}$ no ano de 2014. A foto vencedora retrata o pôr do sol atrás da ponte Hélio Serejo ${ }^{2}$, refletido nas águas do rio Paraná.

Após essa exposição estão sendo realizados eventos diversificados para atrair turistas dos quais podemos destacar: paraquedismo e competições esportivas como corrida, triatlo e ciclismo, uma forma de explorar as belezas paisagísticas e o potencial que existe na estância.

Além dos pescadores, os turistas que mais visitam o município são os que buscam o turismo de Sol e Praia. Os locais preferidos por eles são a Praia da Orla e o Figueiral. Esses atrativos ficam repletos de turistas no verão, principalmente durante as festas de Final de Ano e no Carnaval. Entretanto, a cidade enfrenta algumas dificuldades para alavancar o turismo, entre elas a sazonalidade. A cidade tem momentos de intensa visitação em poucos períodos do ano, ou seja, somente em períodos de férias escolares e feriados como Carnaval a cidade recebe uma quantidade significativa de turistas que faz movimentar a economia, sendo que o município tem potencial para desenvolver a atividade turística durante todo o ano. Por outro lado, Camargo declara que uma grande quantidade de turistas em Presidente Epitácio também causa alguns transtornos:

[...] em períodos de alta temporada o excesso do contingente populacional transitório pode causar malefícios oriundos da falta de estrutura adequada para suportar a demanda, instaurando desconforto e descontentamento para parcelas significativas da população, em decorrência do aumento do custo de bens de consumo local ou pela escassez de determinados produtos (CAMARGO, 2008, p. 54).

Também podemos salientar a pesca predatória como outro empecilho para o desenvolvimento do turismo no município pois esta prática provoca a diminuição da população de peixes no reservatório.

\footnotetext{
${ }^{1}$ Programa de televisão exibido aos domingos pela Rede Globo.

${ }^{2}$ Ponte construída sobre o Rio Paraná que interliga os estados de São Paulo e Mato Grosso do Sul.

Colloquium Socialis, Presidente Prudente, v. 01, n. Especial 2, Jul/Dez, 2017, p.844-852. DOI: 10.5747/cs.2017.v01.nesp2.s0238
} 
Outro problema a ser enfrentado é o turismo sexual. Cintra (2010), retrata este problema no município de Presidente Epitácio, e segundo ela " embora mascarado [...] sua existência reflete, de fato, em um dos problemas mais graves da comunidade receptora, que, no entanto, pouco se discute e quase nada se faz para se solucionar esse impacto que vem crescendo juntamente com o turismo" (CINTRA, 2010, p. 101),

De acordo com Souza e Santos (2011) o município tem um grande potencial para o turismo mas falta infraestrutura, capacitação de pessoal, organização e investimentos na área.

Também podemos destacar a falta de sensibilização e educação ambiental aliada à inexistência de um planejamento que ocasionam na falta de valorização dos espaços naturais e históricos. O reconhecimento da vocação turística e da preservação dos atrativos são fundamentais para a melhoria do turismo no município.

\section{CONCLUSÃO}

Como foi visto, o município possui potencialidades para o desenvolvimento da atividade turística. Após a construção da UHE Engenheiro Sérgio Motta o município passou por grandes transformações na paisagem, perdeu diversas regiões, porém, o novo visual, permitiu o incremento de diversas atividades náuticas e a consolidação do turismo de pesca. Além disso, as obras construídas pela CESP contribuíram para melhorar a infraestrutura nos equipamentos de serviços turísticos possibilitando a oferta de locais mais adequados para a prática das atividades. Essas obras são uma forma de minimizar os impactos negativos causados pela construção da usina hidrelétrica. Diante disso, foi aproveitado o potencial existente com a nova paisagem e foram criados novos espaços para o desenvolvimento de atividades turísticas.

$\mathrm{Na}$ atualidade o turismo se apresenta como uma atividade desordenada no município, gerando uma sobrecarga de pessoas no espaço em determinados períodos, e uma ocupação territorial ociosa em outros momentos, o que gera um descontentamento tanto de turistas quanto da população receptora, que pode refletir em uma sensação de ineficiência com relação aos gestores municipais.

Em consulta ao COMTUR - Conselho Municipal de Turismo - foi informado que o Plano Diretor de Turismo está em processo de finalização, e que este documento irá reunir as informações referentes à demanda, inventário, diagnóstico e prognóstico do município, espera-se que desta forma sejam definidas as ações prioritárias para o fomento e crescimento da atividade turística.

Conclui-se que há muito por se fazer para o desenvolvimento da atividade turística. Porém, com um esforço coletivo da população com relação à hospitalidade ao turista, com investimentos públicos em planejamento urbano, com empresários dispostos em realizar investimentos em equipamentos necessários para oferecer uma boa estadia aos turistas como: hotéis, agências de turismo, lojas de artesanato, restaurantes, transportes, entre outros, é possível mudar a realidade e impulsionar o turismo no município.

O turismo é uma alternativa importante para melhorar a qualidade de vida da população e dar mais dinamismo a economia local, em especial no município de Presidente Epitácio onde não há perspectivas de implantação de indústrias e de transformação em pólo econômico, no entanto, é necessário que se faça um planejamento turístico que vise a preservação ambiental, histórica e cultural dos atrativos turísticos do município. No processo de planejamento, é importante integrar a comunidade local, os empreendedores e os representantes do município, bem como realizar ações de sensibilização e de conscientização turística.

Este trabalho buscou demonstrar as atividades turísticas e potenciais de Presidente Epitácio, pois, conforme demonstrado, o município possui um grande potencial turístico em virtude de suas belezas naturais, porém, necessita cada vez mais ser explorado e estruturado 
adequadamente, o que pode ser uma alternativa para a geração de emprego e renda e consequentemente pode contribuir para a melhoria de qualidade de vida da população.

\section{REFERÊNCIAS BIBLIOGRÁFICAS}

BOMFIM, Luiz C. E. O turismo como alternativa de desenvolvimento local no município de Presidente Epitácio: representações socias e culturais de identidade local. 2007. 102 f. Dissertação (Mestrado) Programa de Pós-Graduação em Desenvolvimento Local, Universidade Católica Dom Bosco, Campo Grande, 2007.

CAMARGO, Keila B. R. de. Estudo do turismo na perspectiva geográfica no município de Presidente Epitácio. 2008. 218 f. Dissertação (Mestrado) Programa de Pós-Graduação em Geografia, Universidade Estadual Paulista, Rio Claro, 2008.

CAMARGO, Keila B. R. de; SILVA, Carlos H. C. da. O turismo no município de Presidente Epitácio: produção e consumo do espaço. Geografia, Rio Claro, v. 30, n. 2, p. 241-254, mai./ago. 2005.

CINTRA, Glaucia A. R. Análise do turismo no sudoeste paulista: os casos de Presidente Epitácio e Rosana. 2010. 161 f. Tese (Doutorado)-Programa de Pós-Graduação em Geografia, Universidade Estadual Paulista, Rio Claro, 2010.

COMPANHIA ENERGÉTICA DE SÃO PAULO-CESP. Relatório de impacto ambiental-RIMA. São Paulo: Consórcio THEMAG/ENGEA/UMHA, 1994. v. 1.

GIL, Antonio C. Métodos e técnicas de pesquisa social. São Paulo: Atlas, 1994.

SANTOS, Ricardo dos; LEAL, Antonio Cezar. Análise Ambiental da Estância Turística de Presidente Epitácio - São Paulo - Brasil. In: 12 Encuentro de Geógrafos de América Latina, 2009, Montevideo - Uruguai. 12 Encuentro de Geógrafos de América Latina. Montevideo : Universidad de la República, 2009. p. 1-15. Disponível em:

<http://observatoriogeograficoamericalatina.org.mx/egal12/Geografiasocioeconomica/Geografiat uristica/69.pdf> Acesso em: 08 de março de 2017.

SÃO PAULO. Presidente Epitácio. Plano Diretor. Disponível em: <http://www.presidenteepitacio.sp.gov.br/?pagina=plano_diretor.html> Acesso em: 26 de setembro de 2017.

SÃO PAULO. Secretaria de Turismo. Estâncias. Disponível em:

<http://www.turismo.sp.gov.br/dade/estancias.html> Acesso em: 08 de fevereiro de 2017.

SOUZA, Marcos B. de; OLIVEIRA, Sérgio D. de. Atividades turísticas em áreas próximas ao lago artificial da usina hidrelétrica Engenheiro Sérgio Motta (Porto Primavera): estudo do município de Presidente Epitácio (estado de São Paulo, Brasil). Revista Geográfica de América Central, [S.I.], v. 2, n. 47E, feb. 2012. ISSN 2215-2563. Disponível em:

<http://www.revistas.una.ac.cr/index.php/geografica/article/view/1874>. Acesso em: 10 de maio de 2017.

SOUZA, Marcos B. de; SANTOS, Ricardo dos. Atividades turísticas e qualidade de vida: estudo do município de Presidente Epitácio (estado de São Paulo, Brasil). Revista Geográfica de América Central, [S.I.], v. 2, n. 47E, feb. 2012. ISSN 2215-2563. Disponível em: 
<http://www.revistas.una.ac.cr/index.php/geografica/article/view/3127>. Acesso em: 16 de maio de 2017. 